\title{
Demyelination in the Brain as a Paraneoplastic Disorder: Candidates Include Some Cases of Multiple Sclerosis
}

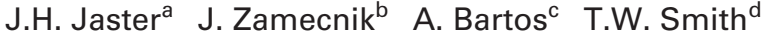 \\ a London Corporation, Grand Prairie, Tex., USA; ${ }^{b}$ Department of Pathology and Molecular Medicine, 2nd Faculty \\ of Medicine, ' ${ }^{\mathrm{D}}$ epartment of Neurology, 3rd Faculty of Medicine, Charles University, Prague, Czech Republic; \\ ${ }^{\mathrm{d}}$ Department of Pathology (Neuropathology), University of Massachusetts, Worcester, Mass., USA
}

We read with interest the epidemiology report of Sumelahti et al. [1] regarding the incidence of cancer in multiple sclerosis (MS) patients in Finland. The incidence of hematologic malignancies was clearly somewhat elevated in MS patients compared to the general population, and the incidence of central nervous system tumors was markedly elevated in MS patients. The high concurrence rate of certain types of malignancies with MS was unexpected and difficult to explain. In the case of hematologic malignancies the authors suggested a potential common infectious etiology, but then acknowledged several factors which argue against this possibility. In the case of brain tumors, which also had a strong temporal correlation with MS, the authors suggested a potential 'misclassification', but again acknowledged factors which argued against this.

We believe that the authors' [1] data collection and results were substantially correct. Their results may correlate well with recent isolated case reports of demyelination in the brain as a paraneoplastic disorder [2-6]. These reports have described a preponderance of hematologic malignan- cies [2, 3] and brain tumors [4] together with brain demyelination in the form of MS [3] as well as with other manifestations of demyelination in the central nervous system such as acute disseminated encephalomyelitis [2], large tumor-like demyelinating lesions [5], optic neuritis [6], and Devic's syndrome [6].

Recently a group of neuropathologists tabulated decades of pathologically confirmed reports of brain tumors concurring with MS [7]. They reported that women were affected much more frequently than men, and that the mean age at diagnosis was 48.5 years [7]. These findings [7] were consistent with those of Sumelahti et al. [1]. The report [7] attempted unsuccessfully to provide an explanation for this phenomenon, and it also failed to mention recent reports of demyelination in the brain as a paraneoplastic disorder.

We believe that the epidemiologic data provided by Sumelahti et al. [1] confirm the demographic pattern revealed by tabulated neuropathologic data [7] and support the recent clinical observations of demyelination in the brain as a paraneoplastic disorder.

\section{References}

1 Sumelahti ML, Pukkala E, Hakama M: Cancer incidence in multiple sclerosis: a 35 -year follow-up. Neuroepidemiology 2004;23:224227.

2 Jaster JH, Niell HB, Dohan FC Jr, Smith TW: Demyelination in the brain as a paraneoplastic disorder: candidates include some cases of leukemia and non-Hodgkin's lymphoma. Ann Hematol 2003;82:714-715.

3 Jaster JH, Niell HB, Dohan FC Jr, Smith TW: Therapy-related acute myeloblastic leukemia after mitoxantrone treatment in a patient with MS. Neurology 2003;60:1399-1400.

4 Jaster JH, Dohan FC Jr, O'Brien TF: Demyelination in the brain as a paraneoplastic disorder: candidates include some cases of semino$\mathrm{ma}$ and central nervous system lymphoma. $\mathrm{J}$ Neurol Neurosurg Psychiatry 2002;73:352.

5 Jaster JH, Bertorini TE, Dohan FC Jr, et al: Solitary focal demyelination in the brain as a paraneoplastic disorder. Med Pediatr Oncol 1996;26:111-115.

6 Jaster JH, Smith TW: Demyelination in the brain as a paraneoplastic disorder. Br J Radiol 2004; $77: 899$.

7 Shuangshoti S, Hjardermaal GM, Ahmad Y, et al: Concurrence of multiple sclerosis and intracranial glioma. Clin Neuropathol 2003;22: 304-308.

\section{KARGER}

Fax +4161306 1234 E-Mail karger@karger.ch www.karger.com
J. Howard Jaster, MD London Corporation 570 Bridle Path 1117

Grand Prairie, TX 75050 (USA)

Tel.+19722660011,E-Mail harbert38104@yahoo.com 